\title{
Handling and Pathology Reporting of Gastrointestinal Endoscopic Mucosal Resection
}

\author{
Bita Geramizadeh ${ }^{1,2^{*}}$, David A. Owen ${ }^{3}$
}

1. Department of Pathology, Shiraz University of Medical Sciences, Shiraz, Iran

2. Transplant Research Center, Shiraz University of Medical Sciences, Shiraz, Iran

3. Deptartment of Pathology, Vancouver General Hospital and University of British Columbia, Vancouver, BC, Canada

\footnotetext{
* Corresponding Author:

Bita Geramizadeh, MD

Medical Faculty, Department of Pathology, Transplant Research Center, Shiraz University of Medical Sciences, Shiraz, Iran

Telefax: + 987136473238

Email: geramib@sums.ac.ir

Received: 23 Jun. 2016

Accepted: 11 Nov. 2016
}

\begin{abstract}
Endoscopic mucosal resection (EMR) is a non-invasive alternative to surgery that is now frequently used for resection of early lesions in both upper and lower parts of the gastrointestinal (GI) tract. One of the main advantages of these techniques is providing tissue for histopathological examination. Pathological examination of endoscopically resected specimens of GI tract is a crucial component of these procedures and is useful for prediction of both the risk of metastasis and lymph node involvement.
\end{abstract}

As the first step, it is very important for the pathologist to handle the EMR gross specimen in the correct way: it should be oriented, and then the margins should be labeled and inked accurately before fixation.

In the second step, the EMR pathological report should include all the detailed information about the diagnosis, grading, depth of invasion (mucosa only or submucosal involvement), status of the margins, and the presence or absence of lymphovascular invasion.

The current literature (PubMed and Google Scholar) was searched for the words "endoscopic mucosal resection" to find all relevant publications about this technique with emphasis on the pathologist responsibilities.

\section{KEYWORDS:}

Endoscopic mucosal resection, Gastrointestinal tract, Histopathological examination, Invasion

Please cite this paper as:

Geramizadeh B, Owen D. Handling and Pathology Reporting of Gastrointestinal Endoscopic Mucosal Resection. Middle East J Dig Dis 2017;9:5-11.DOI: 10.15171/mejdd.2016.45

\section{INTRODUCTION}

Endoscopic mucosal resection (EMR) is a safe technique, which was first introduced in Japan in 1978 for the treatment of early gastric cancer. It was then adopted in Europe and North America for the treatment of Barrett's esophagus (BE) and associated lesions. ${ }^{1,2}$

With advances in endoscopic techniques, EMR has become an approved treatment for effective removal of non-invasive lesions and mucosal or superficial submucosal invasive lesions of the esophagus, stomach, duodenum and colon. ${ }^{2}$ Resection allows for endoscopic diagnosis, cure and/or definitive staging of upper and lower gastrointestinal (GI) mucosal tumors. So this technique is superior to traditional biopsy, which rarely allows accurate staging. ${ }^{3}$

EMR has been used in different types of malignant and premalignant lesions of esophagus, stomach, duodenum, and colon. In addition some submucosal lesions such as neuroendocrine tumors can be resected by EMR. ${ }^{4-8}$

An important component to achieve optimum results and outcomes 
in endoscopically resected lesions is accurate pathological assessment, because this has a great impact on therapeutic decisions and patients' follow-up and survival. Applying a standard protocol by pathologists for handling, grossing, staging and reporting of EMR specimens is critical to provide consistent and accurate diagnosis and with follow-up of the patient by the endoscopist. ${ }^{9-11}$

In this article, we will try to review different techniques and indications of EMR for resection, diagnosis, and staging of upper and lower GI lesions with the emphasis on the pathological handling and reporting of the above mentioned specimens.

\section{INDICATIONS FOR EMR:}

EMR is a safe method for definitive treatment of superficial premalignant and well to moderately differentiated malignant lesions of the GI tract in the absence of lymph node or distant metastases (T1m N0 M0). It is also very helpful for staging early GI cancers, because it can provide a larger specimen than conventional biopsies. ${ }^{12-14}$ Some of the important indications for EMR are listed below:

* Barrett esophagus (BE): Interest in EMR for the treatment of $\mathrm{BE}$ with or without dysplasia or intramucosal carcinoma is growing. Being safe, creating enough specimens for accurate pathological staging, and the potential for cure, are reported benefits of EMR in this setting. ${ }^{15-22}$ Lesions, which are $2 \mathrm{~cm}$ or less, well to moderately differentiated, and limited to mucosa are suitable candidates for this procedure. EMR is also an alternative to surgery for treatment of adenocarcinomas limited to the superficial submucosa. ${ }^{15}$ All of these criteria are also applicable for esophageal squamous cell carcinoma and its precursors. ${ }^{18}$

* Early gastric adenocarcinoma: Criteria for treatment with EMR, include well to moderately differentiated intestinal type adenocarcinomas, with the following characteristics:

1. Lesions that are well differentiated and up to 3 $\mathrm{cm}$ in diameter without ulceration or ulcer scar

2. Superficial submucosal invasive ( $\mathrm{sm} 1)$ lesions less than $2 \mathrm{~cm}$ in diameter with ulcer or ulcer scar

3. $\mathrm{sm} 1$ lesions less than $2 \mathrm{~cm}$ in diameter without ulcer or ulcer scar

4. Poorly differentiated cancer less than $1 \mathrm{~cm}$ in diameter. ${ }^{23-26}$

Another indication for EMR is gastric neuroendocrine tumors, which are less than $1 \mathrm{~cm}$ in diameter. $^{27}$

* Duodenum: EMR has been reported for the treatment and staging of duodenal tumors not involving major papillae. ${ }^{27}$ Also it has been used for non-ampullary adenomas, neuroendocrine tumors, and submucosal lesions. The procedure at this location seems to have more complications than other sites, because of the thin duodenal wall and its high vascularity. ${ }^{28,29}$

* Colon: EMR is commonly used for the resection of laterally spreading benign large and flat lesions and early adenocarcinomas of the colon. Lesions recommended for EMR in colon are as listed below:

1. Well or moderately differentiated tumors confined to the mucosa

2. Type 0-IIa lesions smaller than $2 \mathrm{~cm}$

3. Type $0-\mathrm{IIb}$ lesions smaller than $1 \mathrm{~cm}$

4. Type 0 -IIc lesions smaller than $1 \mathrm{~cm}^{20-33}$

5. Rectal carcinoid ${ }^{27}$

\section{CONTRAINDICATIONS TO EMR:}

* Suspicious lymph node involvement or metastasis

* Suspicious submucosal invasion that can be predicted by the non-lifting sign, i.e. the failure of a lesion to elevate above the surrounding mucosa after submucosal injection beneath the lesion. There may be a false positive non-lifting sign for lesions that have been biopsied prior to EMR. This is because biopsy causes fibrosis within the lesion. Decreasing the time interval between the biopsy sampling and EMR will reduce the risk of this false positive result. ${ }^{34-35}$

\section{TECHNIQUES OF EMR :}

There are several techniques for EMR, including injection-assisted, cap-assisted, and ligation-assisted techniques. The basic principle in all the methods is identification and demarcation of the lesion, submucosal injection of solutions such as saline, methylene 
blue, and epinephrine to lift the lesion, and endoscopic resection either by ligation, cap-assisted suction technique, or the rubber band technique. In the cap-assisted technique, the area of resection is suctioned into the cap and then grasped with a snare for resection. For the rubber band technique, the tissue is suctioned by a rubber band forming a "pseudopolyp." The banded "pseudopolyp" containing the tumor is then cut with a snare at its base. An important point is to ensure that some of the uninvolved surrounding mucosa and/or submucosa remains attached to the tumor. ${ }^{36-40}$

\section{HISTOPATHOLOGICAL EXAMINATION OF THE EMR/ESD SPECIMENS:}

Non-invasive alternatives to the methods of mucosal resections for high grade premalignant and superficial malignant lesions of the GI tract, such as BE with dysplasia or intramucosal carcinoma are ablative therapies. EMR associated with ablation therapies increases the risk of further strictures. However, all of the ablative therapies have a main disadvantage of the lack of tissue for histopathological examination. ${ }^{41}$ The role of pathologists in reporting endoscopic resections is to confirm the endoscopic diagnosis and to provide information that helps clinicians to determine further management, staging, and follow-up. ${ }^{42}$

\section{HANDLING THE GROSS SPECIMEN:}

The specimen should arrive at the pathology lab in the fresh state, with the margins be oriented properly by the endoscopists in the endoscopy room. In most situations, labeling the 12 o'clock position is enough for complete orientation, however it is better to also label oral (o), anal (a), distal (d), or proximal (p) margins. The EMR/ESD specimens are usually round to oval. ${ }^{43}$

What are the tasks of the pathologist in handling the gross specimen?:

3) The base and the lateral mucosal margins should be inked with different colors.

4) The resected specimens should be stretched and fixed mucosal side up onto a rigid support such as a block of wax or a corkboard. Immediate pinning and fixing of the specimen helps the tissue to be preserved with regard to size, shape, and orientation. The pins should preferably not perforate neoplastic areas since this might alter the accuracy of histological diagnosis. Overextension of the specimen should also be avoided as it can cause destruction of the tissue. ${ }^{44,45}$

5) A photograph with a ruler in place is helpful for mapping the lesion/margins and comparing the macroscopic appearance of the lesion with the endoscopic findings. If photography is not feasible, a drawing may be helpful. In some cases, the specimens need to be evaluated using a dissecting microscope to confirm the orientation and assess the margins. ${ }^{45}$

6) The specimens are best fixed for at least 12 hours in $10 \%$ buffered formalin. ${ }^{46}$

7) After fixation the specimens should be serially sectioned at 2-3 $\mathrm{mm}$ intervals parallel to the long axis (not less than $2 \mathrm{~mm}$ ). ${ }^{46}$ The specimen must be entirely embedded. The sections should be sequentially embedded in one or two cassettes, routinely processed, and stained with Hematoxylin and Eosin. ${ }^{37}$ No more than 4 pieces are placed into one cassette..$^{9}$ If the specimen is wide enough, radial sections should be submitted as well. When the gross lesion is located at more than $1 \mathrm{~mm}$ from the margin, both ends of the specimen should be submitted en face. For small EMR specimens, perpendicular sections are better to include both the lesion and margin. EMR specimens removed piecemeal and fragmented (up to $26 \%$, especially in band ligation technique) are difficult to stage accurately. ${ }^{41-46}$ Fragmentation of the specimen should be recorded in the gross description. ${ }^{9}$

\section{HOW TO ORGANIZE A PATHOLOGY REPORT:}

The type of mucosa and the tissue present should be recorded.

The main parts of the diagnosis and microscopic description should include below-mentioned components; ${ }^{41-47}$

1) Size of the specimen

2) Histological type

3) Grade of dysplasia (low or high grade) and tumor differentiation.48 In some reports, the authors recommend mentioning the percentage of each grade of dysplasia, because it may guide further ablation therapy especially in BE. ${ }^{46}$ 
4) Vascular and perineural involvement

5) Status of the resected margin, which has been inked, should be evaluated; however the presence of cautery artifact will confirm the true margin, although in about $10 \%$ of the EMR lesions in the esophagus cautery can obscure histological details such as dysplasia. This problem is much less common in gastric EMRs. Both lateral and circumferential margins should be reported. ${ }^{48,49}$ In Barrett's specimen, it is also better to report the presence of metaplastic tissue in the margin. ${ }^{47}$ Assessment of the margins is crucial to determine the adequacy of the procedure, and the presence of tumor cells at the margins indicates an incomplete resection. Although only the presence of carcinoma cells at the inked or cauterized margins is considered positive, measurement of the distance between the tumor and the closest margin should be provided. ${ }^{50}$ In fragmented and piecemeal specimens, evaluation of the mucosal resection margins is not definitive and the only assessable margin is the deep margin. ${ }^{9}$

6) Depth of invasion: The most important prognostic marker in EMR specimens is the depth of invasion. It is the best predictor of recurrence, metastasis, and lymph node invasion. ${ }^{41}$ It can be reported as " $\mathrm{m}$ and sm" according to the involvement of mucosa $(\mathrm{m})$ and submucosa $(\mathrm{sm}) .{ }^{12}$

Mucosal involvement is classified as $\mathrm{ml}$ (when the lesion is confined to the epithelium), $\mathrm{m} 2$ (when the lesion has involved both the epithelium and lamina propria), and $\mathrm{m} 3$ (when the muscularis mucosae is also involved).

Submucosal involvement is further sub-classified as sm1 (if there is only invasion of the upper third of the submucosa up to less than 500 microns), sm2 (for invasion of the middle third of the submucosa), and sm3 (when there is invasion of the lower third of the submucosa).

Muscularis propria may not be present in many cases, and thus determining where the submucosa ends can be difficult to establish. ${ }^{15}$

Alternatively, it is appropriate to measure the depth of submucosal invasion with a micrometer. Likewise, measuring the distance between tumor and the deepest resection margin is recommended. Tumor cells at that deeper margin indicate that the tumor was not completely excised. ${ }^{9}$

7) Presence of peptic ulcer or scar should be recorded in the pathology report. ${ }^{9}$

Pitfalls in determining the depth of invasion: In specimens from BE, a confusing finding is the presence of a double muscularis mucosae (MM). This change is related to the pathogenesis of Barrett's i.e. it seems that BE is not only an epithelial but also a stromal abnormality. ${ }^{47}$ In this situation the MM will be duplicated and outer layer can be misdiagnosed as muscularis propria. The deeper layer represents the original MM and the superficial layer is the new MM. Pathologists who deal with EMR specimens need to know about this duplication, so as not to consider the outer layer of the MM as muscularis propria. Involvement of the inner or outer layer of the MM has the same prognostic implications. The superficial MM separates the lamina propria into two compartments and these are not different in their vascular constituents. Therefore true submucosal invasion is present only when the invasive component extends beyond the original (deep) layer of MM. ${ }^{51}$

In specimens where the muscularis mucosa is disrupted by ulceration or tumor invasion, the muscularis mucosa level can be estimated by drawing a line to connect the edges of the remaining muscularis mucosae. ${ }^{52,53}$

\section{ARTIFACTS OF EMR:}

There are a number of artifacts that can make the histopathological interpretation difficult and pathologists need to be aware of them, as below:

1) Hemorrhage

2) Cautery distortion

3) Loss of the surface epithelium

4) Fibrin deposition that may occur at the time of suction.

5) Tissue contraction and folding of the edge of the specimen secondary to fixation in formaldehyde. ${ }^{53}$

\section{POST MUCOSAL RESECTION SPECIMENS (FOLLOW-UP):}

Another important step in the follow-up of patients with endoscopic resection is the evaluation of postresection biopsy samples to exclude recurrence. ${ }^{46}$ The 
pathologist needs to know about the previous EMR procedure at the time of examining the follow-up biopsy so as not to over-diagnose malignancy. For example, so-called buried atypical glands may mimic dysplasia or cancer. In this situation atypical glands are displaced under the newly formed re-epithelialized surface mucosa. These foci may be confused with invasive carcinoma. Moreover, biopsy tissues obtained during the first 2 weeks after endoscopic resections can show clear cell degeneration and stromal regenerative changes in areas of ischemia, which also can be confused with malignancy. ${ }^{55}$

\section{CONCLUSION:}

Ability of the pathologist to establish an accurate diagnosis and provide an accurate staging of the invasion (if present) in EMR specimens, is a very important part of this procedure. There seems to be more inter-observer agreement in EMR pathological reporting than with endoscopic mucosal biopsies. This is probably related to larger samples and identification of mucosal landmarks. ${ }^{56}$ In the experience in Shiraz, we've got many colonic polyps, majority of which with the conventional polypectomy method, however we're receiving more and more EMR specimens, which emphasizes on proper handling and suitable pathologic reporting..$^{57,58,59}$

\section{CONFLICT OF INTEREST:}

The authors declare no conflict of interest related to this work.

\section{REFERENCES}

1. Soetokno R, Kaltenbach T, Yeh R, Gotoda T. Endoscopic Mucosal Resection for Early Cancers of the Upper gastrointestinal Tract. J Clin Oncol 2005;23:4490-8.

2. Faivre J, Bory R, Moulinier B. Benign tumors of oesophagus: Value of endoscopy. Endoscopy 1978;10:264-8. doi: 10.1055/s-0028-1098306

3. Lee JK, Enns R. Endoscopic mucosal resection in the setting of Barrett's esophagus. Can $J$ Gastroenterol 2007;21:151-4. doi:10.1155/2007/198728

4. Ahmad NA, Kochman ML, Long WB, Furth EE, Ginsberg GG. Efficacy, safety, and clinical outcomes of endoscopic mucosal resection: a study of 101 cases. Gastrointest Endosc 2002;55:390-6. doi : 10.1067/mge.2002.121881

5. Park SM, Ham JH, Kim BW, Kim JS, Kim CW, Kim JI, et al. Feasibility of Endoscopic Resection for Sessile Non- ampullary Duodenal Tumors: A Multicenter Retrospective Study. Gastroenterol Res Pract 2015;2015:692492. doi: 10.1155/2015/692492.

6. Moss A, Bourke MJ, Williams SJ, Hourigan LF, Brown G, Tam W, et al. Endoscopic mucosal resection outcomes and prediction of submucosal cancer from advanced colonic mucosal neoplasia. Gastroenterology. 2011;140:1909-18. doi: 10.1053/j.gastro.2011.02.062.

7. Chandrasekhara V, Ginsberg GG. Endoscopic mucosal resection: Not your Father's polypectomy anymore. Gastroenterology 2011;141:42-9. doi: 10.1053/j.gastro.2011.05.012.

8. Lee HJ, Kim SB, Shin CM, Seo AY, Lee DH, Kim N,et al. A comparison of endoscopic treatments in rectal carcinoid tumors. Surg Endosc 2016;30:3491-8. doi: 10.1007/ s00464-015-4637-4.

9. Mojtahed A, Shimoda T. Proper pathologic preparation and assessment of endoscopic mucosal resection and endoscopic submucosal dissection specimens.Tech Gastrointest Endosc 2011;13:95-99. doi: 10.1016/j.tgie.2011.02.007

10. Larghi A, Lightdale CJ, Memeo L, Bhagat G, Okpara N, Rotterdam H. EUS followed by EMR for staging of highgrade dysplasia and early cancer in Barrett's esophagus. Gastrointest Endos 2005;62:16-23. doi:10.1016/S00165107(05)00319-6

11. Moss A, Bourke MJ, Hourigan LF, Gupta S, Williams SJ, Tran K. Endoscopic resection for Barrett's high-grade dysplasia and early esophageal adenocarcinoma: an essential staging procedure with long-term therapeutic benefit. $A m J$ Gastroenterol 2010 ;105:1276-83. doi:10.1038/ajg.2010.1

12. Participants in Paris Workshop. The Paris endoscopic classification of superficial neoplastic lesions: esophagus, stomach, and colon. Gastrointest Endoscopy 2003;58: S3S43. doi: 10.1016/S0016-5107(03)02159-X

13. Brahmania M, Lam E, Telford J, Enns R. Endoscopic mucosal resection: Early experience in British Columbia. Can J Gastroenterol 010;24:239-244. doi: 10.1155/2010/897473

14. Scudiere JR, Montgomery EA. New treatments, new challenges : Pathology's perspective on esophageal carcinoma. Gastroenterol Clin N Am 2009;38:121-33.

15. Sharma P, Katzka DA, Gupta N, Ajani J, Buttar N, Chak A, et al. Quality Indicators for the Management of Barrett's Esophagus, Dysplasia, and Esophageal Adenocarcinoma: International Consensus Recommendations from the American Gastroenterological Association Symposium. Gastroenterology 2015;149:1599-1606. Gastroenterology 2015;149:1599-606. doi: 10.1053/j.gastro.2015.08.007.

16. Takeshita K, Tani M, Inoue H, Saeki I, Hayashi S, Honda $\mathrm{T}$, et al. Endoscopic treatment of early esophageal or gastric cancer. Gut 1997;40:123-7. doi:10.1136/gut.40.1.123

17. Inoue H, Fukami N, Yoshida T, Kudo SE. Endoscopic mucosal resection for esophageal and gastric cancers. J Gastroenterol Hepatol. 2002 ;17:382-8. doi: 10.1046/j.14401746.2002.02732.x

18. Ciocirlan M, Lapalus MG, Hervieu V, Souquet JC, Napoléon B, Scoazec JY. Endoscopic mucosal resection for squamous 
premalignant and early malignant lesions of the esophagus. Endoscopy 2007;39:24-9. doi: 10.1055/s-2006-945182

19. Ell C, May A, Gossner L, Pech O, Günter E, Mayer G, et al. Endoscopic mucosal resection of early cancer and highgrade dysplasia in Barrett's esophagus. Gastroenterology 2000;118:670-7. doi: 10.1016/S0016-5107(02)99993-1

20. Nijhawan PK, Wang KK. Endoscopic mucosal resection for lesions with endoscopic features suggestive of malignancy and high-grade dysplasia within Barrett's esophagus. Gastrointest Endosc 2000;52:328-32 . doi: 10.1067/ mge.2000.105777

21. Vieth M, Ell C, Gossner L, May A, Stolte M. Histological analysis of endoscopic resection specimens from 326 patients with Barrett's esophagus and early neoplasia. Endoscopy. 2004;36:776-81. doi: 10.1055/s-2004-825802

22. Chennat J, Konda VJ, Ross AS, de Tejada AH, Noffsinger A, Hart J,et al. Complete Barrett's eradication endoscopic mucosal resection: an effective treatment modality for high-grade dysplasia and intramucosal carcinoma--an American single-center experience. Am J Gastroenterol. 2009 ;104:2684-92. Am J Gastroenterol 2009;104:268492. doi: 10.1038/ajg.2009.465.

23. Ono H, Kondo H, Gotoda T, Shirao K, Yamaguchi H, Saito $\mathrm{D}$, et al. Endoscopic mucosal resection for treatment of early gastric cancer. Gut 2001;48:225-9. doi:10.1136/gut.48.2.225

24. Lee IS, Park YS, Lee JH, Park JY, Kim HS, Kim BS, et al. Pathologic discordance of differentiation between endoscopic biopsy and postoperative specimen in mucosal gastric adenocarcinomas. Ann Surg Oncol 2013;20:42317. doi: 10.1245/s10434-013-3196-y.

25. Amano Y, Ishihara S, Amano K, Hirakawa K, Adachi K, Fukuda R,et al. An assessment of local curability of endoscopic surgery in early gastric cancer without satisfaction of current therapeutic indications. Endoscopy. 1998 ;30:548-52. doi: 10.1055/s-2007-1001342

26. Karaca C, Turner BG, Cizginer S, Forcione D, Brugge W. Accuracy of EUS in the evaluation of small gastric subepithelial lesions. Gastrointest Endosc 2010;71:722-7. doi: 10.1016/j.gie.2009.10.019.

27. ASGE Technology Committee, Hwang JH, Konda V, Abu Dayyeh BK, Chauhan SS, Enestvedt BK, et al. Endoscopic mucosal resection. Gastrointest Endosc. 2015;82:21526. doi: 10.1016/j.gie.2015.05.001

28. Yoshida Y, Matsumoto S. Selection of appropriate endoscopic therapies for duodenal tumors: An open-label study, single-center experience. World $J$ Gastroenterol 2014;20:8624-30. doi: 10.3748/WJG.v20.i26.8624

29. Yamamoto H, Miura Y. Duodenal ESD: conquering difficulties. Gastrointest Endosc Clin N Am 2014 ;24:235-44.

30. Yokota T, Sugihara K, Yoshida S. Endoscopic mucosal resection for colorectal neoplastic lesions. Dis Colon Rectum 1994 ;37:1108-11. doi: 10.1007/BF02049812

31. Conio M, Repici A, Demarquay JF, Blanchi S, Dumas R, Filiberti R. EMR of large sessile colorectal polyps. Gastrointest Endosc. 2004;60:234-41. doi: 10.1016/S0016-

\section{$5107(04) 01567-6$}

32. Carvalho R, Areia M, Brito D, Saraiva S, Alves S, Cadime AT. Endoscopic mucosal resection of large colorectal polyps: prospective evaluation of recurrence and complications. Acta Gastroenterol Belg 2013;76:225-30.

33. Kim MS, Kim NK, Park JH. Intramural recurrence without mucosal lesions after an endoscopic mucosal resection for early colorectal cancer. Ann Coloproctol 2013;293:126-9. doi: $10.3393 /$ ac.2013.29.3.126

34. Uno Y, Munakata A. The non-lifting sign of invasive colon cancer. Gastrointest Endosc 1994;40:485-9. doi: 10.1016/ S0016-5107(94)70216-0

35. Han KS, Sohn DK, Choi DH, Hong CW, Chang HJ, Lim $\mathrm{SB}$, et al. Prolongation of the period between biopsy and EMR can influence the nonlifting sign in endoscopically resectable colorectal cancers. Gastrointest Endosc 2008;67:97-102. doi: 10.1016/j.gie.2007.05.057

36. Terheggen G, Horn EM, Veith M, Gabbert H, Enderle M, Neugebauer A,et al. A randomised trial of endoscopic submucosal dissection versus endoscopic mucosal resection for early Barrett's neoplasia. Gut 2016. pii: gutjnl-2015-310126. doi: 10.1136/gutjnl-2015-310126.

37. Inoue H, Minami H, Kaga M, Sato Y, Kudo SE. Endoscopic Mucosal Resection and Endoscopic Submucosal Dissection for Esophageal Dysplasia and Carcinoma. Gastrointest Endosc Clin N Am 2010;20:25-34, v-vi. doi: 10.1016/j.giec.2009.08.005.

38. Zhou PH, Schumacher B, Yao LQ, Xu MD, Nordmann T, Cai MY, et al. Conventional vs. waterjet-assisted endoscopic submucosal dissection in early gastric cancer: a randomized controlled trial Authors Endoscopy 2014;46:836-842. doi: 10.1055/s-0034-1377580

39. Yamamoto K, Hayashi S, Saiki H, Indo N, Nakabori T, Yamamoto M,et al. Endoscopic submucosal dissection for large superficial colorectal tumors using the "clipflap method". Endoscopy 2015;47:262-5. doi: 10.1055/s0034-1390739.

40. Nemoto D, Hayashi Y, Utano K, Isohata N, Endo S, Lefor AK,et al. A novel retrieval technique for large colorectal tumors resected by endoscopic submucosal dissection: tumor extraction by defecation. Endosc Int Open 2016;4:E93-5. doi: 10.1055/s-0041-107902.

41. Vietha M, Langner C, Neumann H, Takubo K. Barrett's esophagus. Practical issues for daily routine diagnosis. Pathol Res Pract 2012;208:261-8. doi: 10.1016/j.prp.2012.03.001

42. Bejarano PA, Berho M. Examination of Surgical Specimens of the Esophagus. Arch Pathol Lab Med 2015;139:1446-54. doi: 10.5858/arpa.2014-0506-RA.

43. Dautel SHP, Baumbach DR, Oldhafer KJ, Oldhafer KJ, Stang A, Feyerabend B,et al. Single center experience of endoscopic submucosal dissection (ESD) in early Barrett's adenocarcinoma. Surg Endosc 2015;29:1591-7. doi: 10.1007/ s00464-014-3847-5.

44. Chevaux JB, Piesseux H, Jouret-Mourin A, Yeung R, Danse E, Deprez PH . Clinical outcome in patients treated with 
endoscopic submucosal dissection for superficial Barrett's neoplasia. Endoscopy 2015;47:103-12. doi: 10.1055/s0034-1390982.

45. Mino-Kenudson M, Brigge WR, Purocelli WP, Nakatsuka LN, Nishioka NS, Zukerberg LR,et al. Management of superficial Barrett's epithelium-related neoplasms by endoscopic mucosal resection. Clinicopathologic analysis of 27 Cases. Am J Surg Pathol 2005;29:680-6.

46. Nagata K, Shimizu M. Pathological evaluation of gastrointestinal endoscopic submucosal dissection materials based on Japanese guidelines. World J Gastrointest Endosc 2012;4: 489-99. doi: 10.4253/WJGE.v4.i11.489

47. Lewis JT, Wang KK, Abraham SC. Muscularis Mucosae Duplication and the Musculo-fibrous Anomaly in Endoscopic Mucosal Resections for Barrett Esophagus Implications for Staging of Adenocarcinoma. Am J Surg Pathol 2008;32:566-71. doi: 10.1097/PAS.0b013e31815bf8c7

48. Lauwers GY, Ban S, Mino M, Ota S, Matsumoto T, Arai $\mathrm{S}$, et al. Endoscopic mucosal resection for gastric epithelial neoplasms: a study of 39 cases with emphasis on the evaluation of specimens and recommendations for optimal pathologic analysis. Mod Pathol 2004;17:2-8. doi:10.1038/ modpathol.3800012

49. Schlemper RJ, Riddel RH, Borchard F, Borchard F, Cooper HS, Dawsey SM,et al. The Vienna classification of gastrointestinal epithelial neoplasia. Gut 2000;47:251-5. doi:10.1136/gut.47.2.251

50. Odze RD, Lauwers GY. Histopathology of Barrett's esophagus after ablation and endoscopic mucosal resection therapy. Endoscopy 2008;40:1008-15. doi: 10.1055/s-0028-1103416

51. Appleman HD. Adenocarcinoma in Barrett Mucosa Treated by Endoscopic Mucosal Resection. Arch Pathol Lab Med 2009;133:1793-7. doi: 10.1043/1543-2165-133.11.1793.

52. Eguchi T, Nakanishi Y, Shimoda T, Iwasaki M, Igaki H, Tachimori Y,et al. Histopathological criteria for additional treatment after endoscopic mucosal resection for esophageal cancer: analysis of 464 surgically resected cases. Modern Pathology 2006;19;475-80. doi:10.1038/modpathol.3800557

53. Hull MJ, Mino-Kenudson M, Nishioka NS, Ban S, Sepehr A, Puricelli W,et al. Endoscopic Mucosal Resection. An improved diagnostic procedure for early gastroesophageal epithelial neoplasms. Am J Surg Pathol 2006;30:114-8.

54. Agoston AT, Strauss AC, Dulai PS, Hagen CE, Muzikansky A, Fudman DI,et al. Predictors of treatment failure after radiofrequency ablation for intramucosal adenocarcinoma in Barrett esophagus. A multi-institutional retrospective cohort study. Am J Surg Pathol 2016;40:554-62. doi: 10.1097/PAS.0000000000000566.

55. Mitsuhashi T, Lauwers GY, Ban S, Mino-Kenudson M, Shimizu Y, Ogawa F, et al. Post-gastric endoscopic mucosal resection surveillance biopsies: evaluation of mucosal changes and recognition of potential mimics of residual adenocarcinoma. Am J Surg Pathol 2006;30:650-6. doi: 10.1097/01.pas.0000202162.88362.32

56. Worrel SG, Boys JA, Chnadrasorma P, Vallone JG, Dunst
CM, Johnson CS,et al. Inter-Observer variability in the interpretation of Endoscopic mucosal resection specimens of esophageal adenocarcinoma interpretation of ER specimens. J Gastrointest Surg 2016;20:140-4; discussion 1445. doi: 10.1007/s11605-015-3009-7.

57. Geramizadeh B, Keshtkar-Jahromi M. Pathology of Colorectal Polyps: A Study from South of Iran. Ann Colorectal Res 2013;1: 60-2.

58. Geramizadeh B. Molecular Biomarkers of Colorectal Cancer: A Review of Published Articles From Iran. Ann Colorectal Res 2015;3: e30100. 